\title{
Insomnia: can it be treated?
}

\author{
Insônia: é possível tratar? \\ Stella Tavares
}

\author{
Clinical Neurophysiologist, Setor \\ de Polissonografia, Instituto de \\ Psiquitaria, Hospital das Clínicas, \\ Faculdade de Medicina de São \\ Paulo and Hospital Israelita Albert \\ Einstein, São Paulo, SP, Brazil. \\ Correspondence: \\ Stella Tavares \\ Alameda Franca, 1581/113 \\ 01422-001 São Paulo SP - Brasil. \\ Email: stella.tavares@hc.fm.usp.br \\ Conflict of interest: \\ There is no conflict of interest to \\ declare. \\ Received 08 November 2013 \\ Received in final form 11 November \\ 2013 \\ Accepted 19 November 2013
}

Both sleep and wakefulness in excess are signs of illness. Aphorism LXXI - Hippocrates, $5^{\text {th }}$ century BC

$\mathrm{H}$

ippocrates, the father of Medicine, spoke of the importance of sleep through this wonderful aphorism. However, it can be said that it was only in 1929 that the modern era of sleep investigation began, with the description of the electrical activity of the human brain by the German psychiatrist Hans Berger, who created the term "electroencephalography". In Chicago in the 1930s, Loomis, Harvey and Hobart ${ }^{1}$ conducted the first systematic studies of electroencephalographic patterns during human sleep. They reported that sleep was not a continuous process but was characterized by distinct activity patterns that alternated throughout the night in an almost predictable manner. In 1953, rapid eye movement (REM) sleep was described formally by Aserinsky and Kleitman². In 1957, Dement and Kleitman defined the existence of three totally distinct states of consciousness: wakefulness, non-REM sleep and REM sleep³; and in 1959, Jouvet and Michel discovered that in cats, REM sleep was characterized by atony of the axial musculature $\mathrm{e}^{4}$.

These findings, together with technological development, were fundamental to the progress of investigations on sleep and its disorders. In 1997, the first classification of sleep disorders was published ${ }^{5}$ and currently the 2005 version is used ${ }^{6}$. This is now undergoing revision for publication in 2014.

Sleep disorders can be seen to have relevance to all fields of healthcare. Not only are these disorders highly prevalent, but also there is increasing knowledge of the repercussions of a bad night of sleep. For example, obstructive sleep apnea syndrome is currently one of the biggest public health problems, with well-defined cardiovascular risks.

Insomnia is a very frequent complaint in medical consultation offices of any specialty. A study on a Brazilian population ${ }^{7}$ revealed that $35 \%$ of the individuals interviewed presented complaints of insomnia at least three times a week. However, despite all advances in knowledge, insomnia is still a challenge because of the generally complex nature of diagnostic and therapeutic approaches towards this condition. Its symptoms may result from various causes, such as use of medications, medical diseases, psychiatric disorders, poor sleep hygiene or primary sleep disorders, among others. Moreover, insomnia is a risk factor for mental and clinical disorders, substance and alcohol abuse and accidents. Around 57\% of insomniac patients develop some kind of psychiatric condition. Insomnia is a predictive factor for a first episode of depression and for recurrence of depression and anxiety ${ }^{8}$. Therefore, when faced with a patient with a complaint of insomnia, careful investigation to identify factors that might be altering the patient's sleep is essential, so that the correct therapeutic measures are taken.

In this issue of Arquivos de Neuro-Psiquiatria, van der Mollen et al ${ }^{9}$ present a wide-ranging review of primary insomnia, with emphasis on non-pharmacological treatment.

The authors firstly show the definition of insomnia as a symptom, which is important for its diagnostic comprehension. They then go beyond this by emphasizing the current view of insomnia in psychological terms (cognitive components and behavioral factors) and in physiological terms (high metabolic rate, with increased muscle tonus, heart rate and temperature). They also show the neurobiology of insomnia from two perspectives: one pointing towards failure of inhibition of wakefulness and the other considering hyper-alertness to have an important role. Comprehension of these characteristics has a fundamental role in approaches 
towards primary insomnia. Spielman's 3P model ${ }^{10}$, through recognizing individuals who present a "chance" of having insomnia (Predisposing factors), factors that can trigger it (Precipitating factors) and factors that can perpetuate it (Perpetuating factors), certainly also helps in applying nonpharmacological interventions. These are collectively named cognitive-behavioral therapy for insomnia (CBT-i) and are increasingly being shown to be effective ${ }^{11}$. Together with drug treatment, CBT-i is considered to be the standard treatment. Over the long term, it shows greater efficacy because of changes to patients' habits and dysfunctional beliefs and thinking.
The authors make an excellent practical application of patients' complaints and the psychological and neurobiological aspects of insomnia, through correlations with the different types of CBT-i. This review can certainly be recommended for all healthcare professionals, and reading it will certainly help not only in identifying the factors involved but also in directing the treatment. However, as written in the text, CBT-i is not commonly used in clinics because of both the lack of information about this treatment and the scarcity of professionals with specific training in this field. We hope that articles like this will stimulate the growth of non-pharmacological therapy for insomnia within our setting.

\section{References}

1. Loomis AL, Harvey EN, Hobart G. Further observations on the potential rhythms of the cerebral cortex during sleep. Science 1935;82:198-200.

2. Aserinsky E, Kleitman N. Regularly occurring periods of eye motility, and concomitant phenomena, during sleep. Science 1953;118:273-274.

3. Dement W, Kleitman N. Cyclic variations in EEG during sleep and their relation to eye movements, body motility, and dreaming. Electroencephalogr Clin Neurophysiol 1957; 9:673-690.

4. Jouvet M, Michel F. [Electromyographic correlations of sleep in the chronic decorticate \& mesencephalic cat]. C R Seances Soc Biol Fil 1959;153:422-425.

5. American Sleep Disorders Association. Diagnostic classification of sleep and arousal disorders. Sleep 1979;2:1-137.

6. Internacional Classification of Sleep Disorders. 2nd ed. Westchester, II. American Academy of Sleep Medicine. 2005
7. Bittencourt LR, Santos-Silva R, Taddei JA, Andersen ML, de Mello MT, Tufik S. Sleep complaints in the adult Brazilian population: a national survey based on screening questions. J Clin Sleep Med 2009;5:459-463.

8. Ohayon MM, Roth T. Place of chronic insomnia in the course of depressive and anxiety disorders. J Psychiatr Res 2003;37:9-15.

9. Molen YF, LBC Carvalho, LBF Prado, GF Prado. Insomnia: psychological and neurobiological aspects and non-pharmacological treatments. Arq Neuropsiquiatr 2014;72:63-71.

10. Spielman AJ, Glovinsky P. The varied nature of insomnia. In: PJ Hauri (Ed.). Case studies in insomnia. New York: Plenum Press 1991:1-15.

11. Morin CM, Gaulier B, Barry T, Kowatch RA. Patients' acceptance of psychological and pharmacological therapies for insomnia. Sleep 1992;15:302-305. 